\title{
Biosynthesis of Silver Nanoparticles by Pathogenic and Nonpathogenic Strains of Fusarium oxysporum f. sp. lycopersici
}

\author{
Fatma A. Mostafa ${ }^{\#}$ \\ Department of Botany and Microbiology, Faculty of Science, Cairo University, Cairo, Egypt.
}

ANOTECHNOLOGY, a highly promising discipline in science and technology, is the
emerging and novel trend that will redesign the future of several existing know how which
will change every aspect of our lives and leads to the generation of uniqueness in all the streams
of technology. Biological synthesis of metal nanoparticles using microbes is gaining momentum
due to the ecofriendly nature of the organisms which reduce toxic chemicals. Plant pathogenic
fungi produce extracellular degradative enzymes that may be important in pathogenicity.
Biosynthesis of silver nanoparticles was investigated using pathogenic Fusarium oxysporum f.
sp. lycopersici and nonpathogenic strains of the same fungal species. These silver nanoparticles
were characterized by means of UV-vis spectroscopy, transmission electron microscopy
(TEM). UV-visible spectrum of the aqueous medium containing silver ion showed a peak at
420 nm corresponding to the Plasmon absorbance of silver nanoparticles. Transmission electron
microscopy (TEM) micrograph showed formation of well-dispersed spherical silver nanoparticles
with mean sizes 11.20 nm and 15.38 nm for pathogenic and nonpathogenic strains, respectively.

Keywords : Silver nanoparticles, Fusarium oxysporumf. sp. lycopersici, Pathogenic and nonpathogenic strains

\section{Introduction}

Nanotechnology is a rapidly growing field of science; this area has become an integral part of modern technology.

Nanomaterials are increasingly becoming a part of our daily lives. Currently, nanomaterials are produced in the hundreds of thousands of tons. They are used in innovative products and processes (Pulit-Prociak \& Banach, 2016). The incorporation of nanoparticles in the productive sectors is due to their scale $(1 \mathrm{~nm}=10-9 \mathrm{~m})$, which provides higher surface area to volume ratio as well as to their novelty properties. Silver nanoparticles (SNPs) have attracted specific attention due to their potential use in a range of applications, such as electronics, bio-sensing, clothing manufacture, food storage, paints, sunscreens, cosmetics and medical devices (Ishida et al., 2013 and León-Silva et al., 2016 ). SNPs have also a potent antibacterial and antifungal activity and general anti-inflammatory effects. Furthermore, SNPs can improve wound healing and may be exploited to develop dressings for wounds and burns and antibacterial coatings on medical devices to reduce nosocomial infection rates (Rauwel et al., 2015; Azmath et al., 2016 and Pulit-Prociak \& Banach, 2016).

Development of reliable and eco-friendly process for synthesis of metallic nanoparticles is an important step in the field nanotechnology. Some microorganisms, including bacteria, yeast and filamentous fungi play an important role in the remediation of toxic metals through the reduction of the metal ions; therefore, these microorganisms could be employed as nanofactories for nanoparticle production. Several studies have shown that metal nanoparticles, such as gold, silver, gold-silver alloy, selenium, tellurium, platinum, palladium, silica, titanium, zirconium, quantum dots and magnetite can be biosynthesized by bacteria, actinomycetes, fungi and viruses ((Pulit-Prociak \& Banach, 2016).

"Myconanotechnology" is the synthesis of nanoparticles by using fungi which have the potential to provide relatively quick and ecologically "clean" metallic nanoparticles. There are many reports on the mycosynthesis of silver NPs (SNPs) and application of fungi for production of SNPs is potentially exciting

\footnotetext{
\#Corresponding author email : fatmaam73@yahoo.com

DOI :10.21608/ejbo.2017.789.1048

C2017 National Information and Documentation Center (NIDOC)
} 
because of their ability to secrete large amount of proteins, where, the biological synthesis of SNPs is enzymes catalyzed reaction (Kumar et al., 2007 and Birla et al., 2013).

Also, due to their tolerance and metal bioaccumulation ability, high binding capacity, and intracellular uptake, fungi have been of interest in biological production of the metallic nanoparticles. They secrete large amounts of enzymes which are used to reduce silver ions that induce the formation of the metal nanoparticles (Rauwel et al., 2015).

The fungus Fusarium oxysporum can reduce aqueous silver ions extracellularly to generate SNPs. This process likely occurs through the action of both reductase enzymes and electron shuttle quinones. In addition, biological nanoparticle synthesis often yields a more consistent size distribution pattern than other methods due to direct stabilization of the nanoparticles by proteins involved in the synthesis process (Pulit-Prociak \& Banach, 2016).

F.oxysporumf. sp. lycopersici Snyd. et Hans. (FOL) is a pathogenic fungal species that causes soil-borne vascular wilt disease in the tomato (Solanum lycopersicum L.). Non-pathogenic strains of the same species are present in the rhizosphere soil and colonize plant roots, but seem not to invade the vascular system. F. oxysporum, can degrade lignin using ligninolytic extracellular peroxidases and laccase (Michielse et al., 2012).

The aim of this study was designed to investigate the differences among the pathogenic and non-pathogenic strains of Fusarium oxysporum in production of silver nanoparticles and their size.

\section{Materials and Methods}

The fungal strain of Fusarium oxyspoum f. sp. lycopersici (AUMC 1425) and nonpathogenic strain of the same species (AUMC 1422) was kindly obtained from Assiut University Mycological Center (AUMC). The strain was maintained at $4^{\circ} \mathrm{C}$ on PDA slants.

Extracellular synthesis of silver nanoparticles by F. oxysporum.

Fusarium oxysporum was grown up in Erlenmeyer flasks containing $100 \mathrm{ml}$ of malt yeast peptone glucose (MYPG) broth with the following composition $(3 \mathrm{~g} / \mathrm{l}$ malt extract, $3 \mathrm{~g} / \mathrm{l}$ yeast extract, $5 \mathrm{~g} / 1$ peptone, $10 \mathrm{~g} / 1$ glucose,). After 5 days of shaking incubation at $28^{\circ} \mathrm{C}, 150 \mathrm{rpm}$, the biomass was separated from the medium by filtration and washed three times in sterile deionized water. Ten $\mathrm{g}$ of biomass was suspended in $100 \mathrm{ml} \mathrm{AgNO}_{3}$ aqueous solution of $1 \mathrm{mM}$ final concentration. The mixture was left for 72 $\mathrm{h}$ in shaking incubator at $28^{\circ} \mathrm{C}$ in dark conditions. The control was only metal ions without fungal biomass (Ahmad et al., 2003).

\section{Characterization of silver nanoparticles $U V$-visible spectroscopy analysis}

The reduction of silver ions was monitored by measuring the UV-VIS spectrum of the reaction medium after $72 \mathrm{~h}$. The absorbance was recorded at 400-600nm using UV-VIS spectrophotometer (Beckman DU-20 spectrophotometer USA) (Shahverdi et al., 2007).

\section{Characterization of SNPs by transmission electronmicroscopy (TEM)}

Transmission electron microscopy technique was used for studying the detailed structure of nanoparticles i.e. size and shape. For TEM measurements, a drop of synthesized AgNPs was placed on the carbon coated copper grids and kept to dry. After dryness of sample grid was loaded onto a specimen holder. TEM micrographs of the sample were taken using JEOL-JEM100 TEM, Japan. It is the confirmatory test of AgNPs. The crystalline nature of metallic SNPs was confirmed by selected area diffraction pattern (Ahmad et al., 2003).

\section{$\underline{\text { Results and Discussion }}$}

NPs are usually clusters of atoms in the size range of $1-100 \mathrm{~nm}$. The microorganisms take target ions from their environment and by the cell activities through enzymes generated turn the metal ions into the element metal. This process benefits from the development of clean, non-toxic and environmentally acceptable procedures ( $\mathrm{Li}$ et al., 2012; Honary et al., 2013 and Abdulaziz et al.,2015).

It was found that fungi score more advantages over other biological systems because of their high tolerance towards the heavy metals. It is well known that in different culture media conditions and compositions microbial cell responds differently and secretes different metabolites 
and different kinds of proteins and extracellular enzymes (Thakkar et al., 2010). Also, we know that the biological synthesis of SNPs is enzymes catalyzed reaction (Birla et al., 2013).

When strains of Fusarium oxysporium fungal biomass were incubated with silver nitrate salt solution, the colour were exhibited a gradual change to brown color under dark conditions. The colour changed after $72 \mathrm{~h}$ of incubation whereas the control (without fungal mycelium) did not exhibit any change in colour. The change in colour is in agreement with the previous studies, which was considered as a visual indication for the production of colloidal suspension (hydrosol) of silver nanoparticles (Ahmad et al., 2003 and Soni \& Prakash, 2011).

In biosynthesis of silver nanoparticles, the biomass or biological system used normally contains functional groups with reducing capacity, and it interacts with preformed nanoclusters or nuclei of silver metal present in the system to form silver nanoparticles (Zhang et al., 2016). Fungi should secrete specific enzymes or metabolites which are responsible for reduction of silver ions, high growth rate and low cost requirement for production procedure. (Shabani et al., 2013).

In the present study, MYPG medium might promote the extracellular nitrate reductase secretion and hence enhance the synthesis of SNPs. According to Birla et al. (2013), Fusarium oxysporum can reduce aqueous silver ions extracellularly to generate SNPs. This process likely occurs through the action of both reductase enzymes (especially nitrate reductase) and electron shuttle quinones (Kumar et al., 2007 and Ishida et al., 2013).

Characterization of silver nanoparticles by UVVisible spectroscopy

When $F$. oxysporum biomass of different strains were exposed to $\mathrm{Ag}^{+}$ions $\left(\mathrm{AgNO}_{3}, 1\right.$ $\mathrm{mM}$ ), the appearance of dark brown is due to the excitation of surface plasm on resonance in the nanoparticles (Korbekandi et al., 2013). In the present study the formation and stability of the silver nanoparticles in the colloidal solution was monitored by using UV-Vis spectral analysis after completion of reaction for $72 \mathrm{~h}$ (Fig.1).

The UV-vis spectroscopy showed maximum absorption at 420nm (Ravindra. \& Rajasab, 2015) for pathogenic and non-pathogenic Fusarium oxysporum which is specific for the SNPs and are indicating the synthesis of silver nanoparticles and the maximum color intensity was obtained after three days. Beyond three days of incubation, no further increase in intensity was recorded indicating complete reduction of silver ions by the fungal biomass (Ingle et al., 2009). The reduction of metal ions occurs on the surface by the enzymes presented in the fungal cell wall. The absorptions spectra are due to plasmon excitations of particles and this confirms the extracellular synthesis of silver nanoparticles

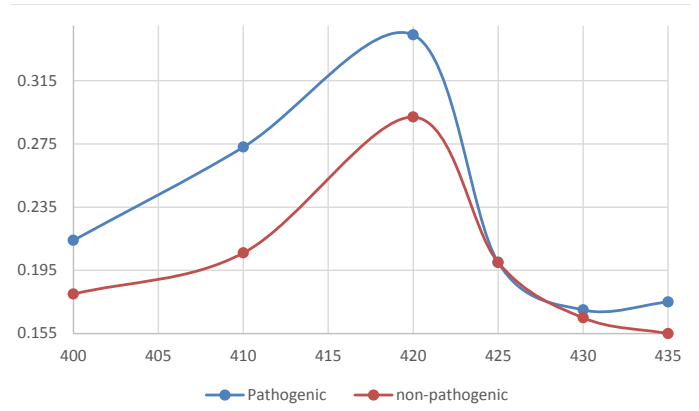

Fig.1. UV-Vis spectra after $72 \mathrm{~h}$ of incubation of fungal biomass in silver nitrate solution.

There was a single peak indicating synthesis of spherical nanoparticles. It is well known that there is a very close relationship between the UV-Vis absorbance spectrum and size and shape of SNPs, with the increase in the particle size, the optical absorption spectra of metal nanoparticles that are dominated by surface plasmon resonances (SPR) shift towards longer wavelengths (red shift). Small blue shift or red shift in the wavelength of the absorbance peak could be related to obtaining SNPs in different shape and size (Rai et al., 2009 and Birla et al., 2013).

\section{TEM analysis of silver nanoparticles}

The direct electron microscopic visualization allows measuring the size and shape of the silver nanoparticles formed. Typical bright-field TEM images of the synthesized silver nanoparticles by non-pathogenic and pathogenic fungus, respectively are shown in Fig. 2(a,b). The silver nanoparticles were predominantly spherical, in shape and single showing a distribution of sizes in the range of 9.19-22.30 nm for nonpathogenic and 7.05-20.23 for pathogenic Fusarium strains. The particle size of silver nanoparticles showed that the average size of particles (average diameter) synthesized by nonpathogenic and pathogenic Fusarium oxysporum f. sp. lycopersici were $15.38 \pm 3.86 \mathrm{~nm}$ and11.20 \pm 3.84, respectively (Ingle et al., 2009). 


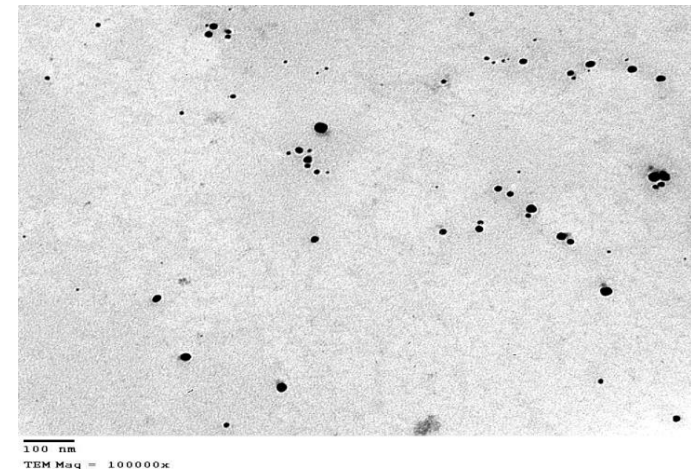

$\mathbf{a}$

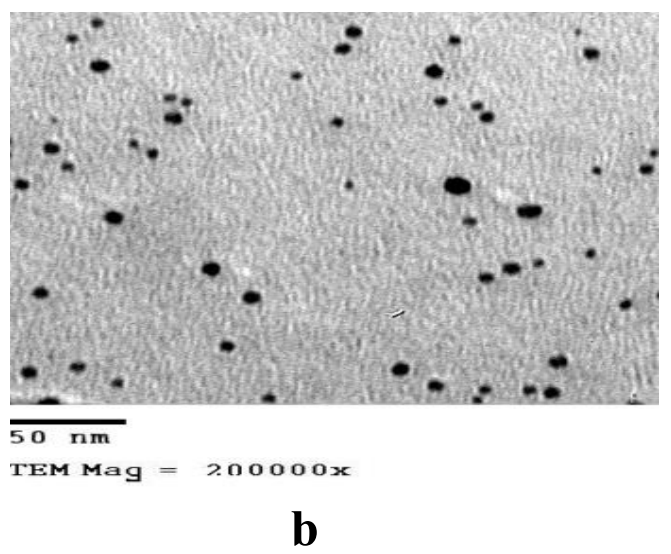

Fig.2a,b. TEM image of silver nanoparticle of nonpathogenic (a) and pathogenic Fusarium oxysporum f. sp. lycopersici (b).

The stability of SNPs is likely to be due to capping with proteins secreted by the fungus (Ahmad et al., 2003). The symmetric graph indicates the optimum conversion of silver ions to SNPs which may be due to the secretion of nitrate reductase, an enzyme responsible for the reduction of silver ions. Proteins have multiple effects on the dispersion, including potential screening of the surface charges that help to maintain the repulsion between the particles, or bridging type interactions (Michielse et al., 2012 and Birla et al., 2013).

\section{Conclusion}

There are no significant differences between the pathogenic and nonpathogenic Fusarium strains in the production of silver nanoparticles nor sizes of particles formed. Also, the synthesized nanoparticles promising sizes for industrial and medical application.

\section{$\underline{\text { References }}$}

Abdulaziz, A., Al juraifani, A. and Ghazwani, A.A. (2015) Biosynthesis of silver nanoparticles by Aspergillus niger, Fusarium oxysporum and Alternaria solani. African Journal of Biotechnology 14 (26), 2170-2174.

Ahmad, A., Mukherjee, P., Senapati, S., Mandal, D., Khan, M. I., Rajiv Kumar, R. and Sastry, M. (2003) Extracellular biosynthesis of silver nanoparticles using the fungus Fusarium oxysporum. Colloids and Surfaces B: Biointerfaces, 28, 313-318.

Azmath, P., Baker, S., Rakshith, D. and Satish, S. (2016) Mycosynthesis of silver nanoparticles bearing antibacterial activity. Saudi Pharmaceutical Journal, 24, 140-146.

Birla, S., Gaikwad, S., Gade, A. and Rai, M. (2013) Rapid synthesis of silver nanoparticles from Fusarium oxysporum by optimizing physicocultural conditions. The Scientific World Journal Article ID 796018, 1-12.

Honary, S., Barabadi, H., Gharaei-Fathabad, E. and Naghibi, F. (2013) Green synthesis of silver nanoparticles induced by the fungus Penicillium citrinum. Tropical Journal of Pharmaceutical Research, 12 (1), 7-11.

Ingle, A., Rai, M., Gade, A. and Bawaskar, M. (2009) Fusarium solani: a novel biological agent for the extracellular synthesis of silver nanoparticles. Journal of Nanoparticle Research, 11, 2079-2085.

Ishida, K., Cipriano, T.F., Rocha, G.M., Weissmüller, G., Gomes, F., Miranda, K. and Sonia Rozental, S. (2013) Silver nanoparticle production by the fungus Fusarium oxysporum: nanoparticle characterisation and analysis of antifungal activity against pathogenic yeasts. Mem Inst Oswaldo Cruz, Rio de Janeiro, 1-9.

Kumar, A., Abyaneh, M. and Gosavi, S. (2007) Nitrate reductase-mediated synthesis of silver nanoparticles from $\mathrm{AgNO}_{3}$. Biotechnology Letters, 29 (3), 439-445.

Korbekandi, H., Ashari, Z., Iravani, S. and Abbasi, S. (2013) Optimization of biological synthesis of silver nanoparticles using Fusarium oxysporum. Iranian Journal of Pharmaceutical Research, 12 (3), 289-298 .

León-Silva, S., Fernández-Luqueño, F. and LópezValdez, F. (2016) Silver nanoparticles (AgNP) in the environment: a review of potential risks on human and environmental health. Water Air Soil Pollution, 22 (7), 306-310.

Li, G., He, D., Qian, Y., Guan, B., Gao, S., Cui, Y., 
Yokoyama, K. and Wang, L. (2012) Fungusmediated green synthesis of silver nanoparticles using Aspergillus terreus. International. Journal of Molecular Science, 13, 466-476.

Michielse, C., Rei jnen, I., Olivain, C., Alabouvette, C. and Rep, M. (2012) Degradation of aromatic compounds through the b-ketoadipate pathway is required for pathogenicity of the tomato wilt pathogen Fusarium oxysporum f. sp. lycopersici. Molecular Plant Pathology, 13(9), 1089-1100.

Pulit-Prociak, J. and Banach, M. (2016) Silver nanoparticles - a material of the future...? Open Chemistry, 14, 76-91.

Rai, M., Yadav, A. and Gade, A. (2009) Silver nanoparticles as a new generation of antimicrobials. Biotechnology Advances, 27, 76-83.

Rauwel, P., Küünal, S., Ferdov, S. and Rauwe, E. (2015) A review on the green synthesis of silver nanoparticles and their morphologies studied via TEM. Advances in Materials Science and Engineering, Article ID 682749, 1-9.

Ravindra, B. and Rajasab, A. (2015) Silver nanoparticles synthesis from different fungal species and their antifungal effect. International Journal of Pharmacy and Pharmaceutical Sciences, 7(5), 165-170.
Shabani, G., Akbarzadeh, A., Mortazavi, M. and Emadzadeh, M. (2013) Evaluation of the antibacterial properties of silver nanoparticles synthesized with Fusarium oxysporum and Escherichia coli. International Journal of Life Sciences Biotechnology and Pharma Research, 2(1), 343-348.

Shahverdi, A., Fakhimi, A., Shahverdi, H. and Minaian, S. (2007) Synthesis and effect of silver nanoparticles on the antibacterial activity of different antibiotics against Staphylococcus aureus and Escherichia coli. Nanotech, Biol, and Med.3,168- 171.

Sintubin, L., De Windt, W., Dick, J., Mast, J., van der Ha, D., Verstraete, W. and Boon, N. (2009) Lactic acid bacteria as reducing and capping agent for the fast and efficient production of silver nanoparticles. Applied Microbiology Biotechnoogy, 184, 741-749.

Soni, N. and Prakash, S. (2011) Factors affecting the geometry of silver nanoparticles synthesis in Chrysosporium tropicum and Fusarium oxysporum. American J. Nanotech. 2 (1), 112-121.

Thakkar, K., Mhatre, S. and Parikh, R. (2010) Biological synthesis of metallic nanoparticles.Nanomedicine : Nanotechnology, Biology and Medicine, 6, 257-262.

Zhang, S., Tang, Y. and Vlahovic, B. (2016) A review on preparation and applications of silver-containing nanofibers. Nanoscale Research Letters, 11, 80.

Received : $21 / 3 / 2017$

Accepted : $1 / 4 / 2017$ 


\title{
البناء الحيوي لجسيمات الفضة النانوية من قبل سلالات الممرضة وغيرمسببة
}

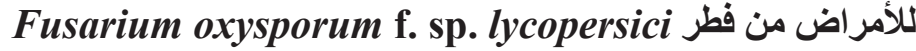

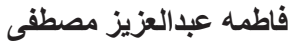 \\ قسم النبات و الميكروبيولوجى ـ كلية العلوم - جامعه القاهره ـ القاهره ـ مصر.
}

\begin{abstract}
تكنولوجيا النانو ستعيد رسم المستقبل وستغير حياتتا.استخدام الميكروبات فى تكوين النانو

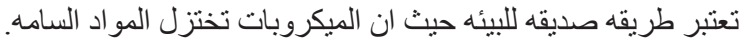

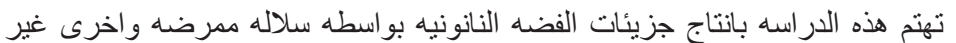

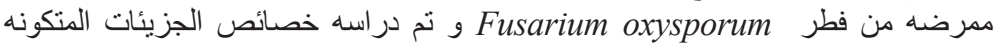

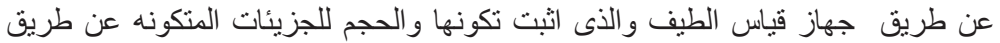

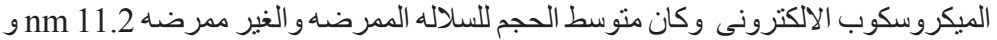

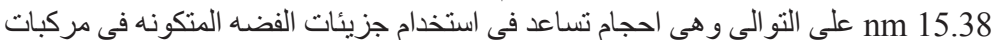

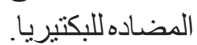


